\title{
O PDRAE e a Contrarreforma Gerencial
}

\author{
Rodrigo de Souza Filho \\ Elcemir Paço Cunha ${ }^{2}$
}

1Professor do Programa de Pós-Graduação em Serviço Social, Universidade Federal de Juiz de Fora.

2Professor do Programa de Pós-Graduação em Direito e Inovação e do Programa de Pós-Graduação em Administração, Universidade Federal de Juiz de Fora.

\section{Introdução}

No ano em que o Plano Diretor da Reforma do Aparelho do Estado (PDRAE) completava 20 anos, a Revista Administração Pública e Gestão Social - APGS divulgou um edital visando recuperar os fatos e avaliar as consequências desta ação política liderada por setores da sociedade civil e executada a partir do Estado.

Como estudiosos da temática da administração pública, além da satisfação de termos sido convidados e podido colaborar com o empreendimento apresentado pelos responsáveis/editores da revista, vimos neste desafio a oportunidade de socializarmos nossa análise sobre os fundamentos do Plano Diretor e, dessa forma, participarmos desse debate coletivo, mesmo sendo de forma breve e tópica. Obviamente, a concepção que evidenciaremos a seguir é de nossa exclusiva responsabilidade.

Do ponto de vista teórico, para uma leitura radicalmente crítica do PDRAE, entendemos o amplo complexo político - constituído pela maquinaria jurídica, política, militar e administrativa (Marx 2011a) - como um dos elementos constituintes da superestrutura ideológica da sociedade. Destacando o fator administrativo desse complexo, conecta-se ele dialeticamente às determinações oriundas das relações sociais de produção (além das reciprocidades que guarda com os demais fatores). Por outro lado, num plano mais concreto, essa dimensão administrativa, como instrumento de materialização da dominação de classe presente na ossatura estatal do amplo complexo político, sofre, também, as influências da sociabilidade e de seu modo de produção históricos (Souza Filho \& Gurgel, 2016).

Disso resulta que esse fator em tela é também uma forma que assume conteúdos bastante concretos. De maneira mais imediata então, a determinação fundamental de uma forma administrativa deve ser encontrada, portanto, na estrutura de classes da sociedade, na medida em que são os interesses antagônicos de classes que conformam os conflitos substantivos numa sociedade, exigindo a intervenção do Estado, através de suas medidas administrativas (Marx, 1996; 2010; 2011a;b) ou, poderíamos simplesmente dizer, através da administração pública.

Nesse sentido, diferentemente das abordagens hegemônicas no campo da análise da administração pública brasileira, a questão central da temática não está relacionada à ineficácia e/ou ineficiência e nem à resistência à introdução de técnicas e procedimentos de "tipo racional-legal" para uma intervenção que se pretenda "republicana". O mais adequado, a partir de nosso ponto de vista teórico-metodológico, seria falar que a administração pública brasileira correspondeu à modulação das relações capitalistas e de dominação de que era forma administrativa.

Em termos gerais, da integração nacional do Império, passando pelo projeto de economia exportadora capitalista, sob hegemonia da oligarquia agrária cafeeira, chegando ao projeto de industrialização sob direção de oligarquias, numa combinação com a burguesia industrial emergente, até o momento de irrupção, consolidação e desenvolvimento da fase monopólica de nosso capitalismo (1950 dias atuais), todos esses processos tiveram por mediação decisiva aquele fator administrativo do complexo político, garantindo a manutenção do pacto de dominação estabelecido em cada momento particular. Ou seja, a administração pública sempre cumpriu suas funções de operacionalizar a expansão capitalista e os projetos de dominação presentes em cada período histórico, propiciando a realização do projeto e dos interesses dominantes em pauta. O que ocorreu sempre foi a exclusão de setores subalternos na participação das decisões sobre as propostas a serem implementadas e sobre a distribuição das riquezas produzidas. Porém, como a incorporação dos setores subalternos não constava dos projetos em tela, a administração pública não pode ser considerada ineficaz tendo como parâmetro a participação desses setores na definição e distribuição das riquezas produzidas. Por outro lado, se a ineficiência aludida significa indicar que os projetos são desenvolvidos através de um grande custo, visto que a administração é permeada de corrupção e apropriação privada de recursos públicos, o equívoco se encontra ao não se perceber que esses instrumentos típicos do efetivo poder econômico privado (que se apropria do fundo público através de diferentes modalidades) são fundamentais para garantir o tipo de pacto de dominação estruturado, que incorpora setores tradicionais da sociedade. Ou seja, os projetos definidos para a industrialização brasileira nunca abriram mão da participação dos setores tradicionais, por conseguinte, os custos para sua incorporação não podem ser vistos como problema de eficiência administrativa. Em suma, ineficiência e ineficácia não podem ser tratadas abstratamente, como se estivessem relacionadas a um projeto industrializante clássico fundado na típica lógica capitalista, ou voltada para a "universalidade de procedimentos" numa orientação republicana.

Sendo assim, em nosso entendimento, o que ocorre ao longo da história da república é a adequação do aparelho administrativo como mediação de primeira ordem às configurações das diferentes fases do projeto de expansão capitalista, a partir sempre de um pacto de dominação que combina a burguesia industrial e a oligarquia agrária e a exclusão (incorporação seletiva e parcial) das classes subalternas. Nesse quadro, em geral, foram reiteradas as bases que 
estruturaram o desenvolvimento de nossa máquina pública, mesmo nos momentos de tentativa de modernização do aparato administrativo.

Esses elementos formam o contexto e os parâmetros que demarcam, em nosso entendimento, o projeto "contrarreformista" expresso no Plano Diretor da Reforma do Aparelho do Estado de 1995.

\section{Os fundamentos do Plano Diretor da Reforma do Aparelho do Estado - 1995}

No contexto da redemocratização brasileira, abre-se pela primeira vez no cenário nacional recente a possibilidade de maior incorporação de demandas populares na estrutura de poder. Mesmo sofrendo as influências internacionais tanto do ponto de vista econômico quanto do ponto de vista político, quer dizer, a incorporação dessas demandas no contexto hegemonizado pelo pensamento neoliberal direcionado para a programática de apoio à internacionalização da economia e para a crítica à intervenção do Estado na área social, a década de 1980, no Brasil, expressou certa resistência ao alinhamento imediato a esse ideário.

Essa resistência contou efetivamente não apenas com o fortalecimento dos setores democráticos da sociedade civil, mas também com certo receio das classes dominantes em abrir mão do apoio do aparato público estatal para a manutenção de seus privilégios, que poderia advir de uma política pautada na refuncionalização do Estado, e sua consequente redução, para efetivar um projeto radical de transnacionalização econômica.

A Constituição Federal de 1988 é emblemática de certa resistência nacional aos preceitos neoliberais in toten. A área social e a questão da administração pública foram os aspectos centrais que expressaram a influência das forças democráticas e populares no destino do país. É preciso enfatizar que essa resistência foi relativa por se apoiar em uma peça constitucional de menor potência do que os interesses materiais dominantes. Em termos práticos, a letra é morta em condições de forças desfavoráveis e sem as mediações de sua efetivação. E esse é caso da miséria brasileira recente.

A universalização e o aprofundamento de direitos de cidadania como dever do Estado prevista na carta magna de 1988, mostra um caminho democrático a ser seguido do ponto de vista político e institucional, portanto, relativamente dissonante à hegemonia internacional. Dessa forma, buscava-se articular um projeto para o país baseado na incorporação de demandas fáticas da classe trabalhadora e de camadas subalternas no desenvolvimento econômico e social. Por isso, a necessidade de um Estado forte na área social de um Brasil historicamente excludente. Não queremos sugerir que o mero quantitativo engendraria tal efeito. Não estamos em devesa de uma íngua burocrática. Uma crítica à burocracia (Paço Cunha, 2015; Souza Filho \& Gurgel, 2016) não deve nos impedir de reconhecer sua funcionalidade em termos quantitativos e qualitativos à execução de um Estado orientado ao atendimento de determinadas demandas fáticas da classe trabalhadora. O certo é que, ainda que com limitações, 1988 marca uma maior porosidade, enquanto projeto, ao impulso de participação das camadas historicamente excluídas.

A situação econômica do país não melhora no contexto imediatamente pós-constituição e, a partir do início dos anos 1990, um novo consenso entre as forças conservadoras foi se constituindo em torno da ideia da inexorabilidade de, mais uma vez, dar continuidade à inserção subordinada do país ao capital internacional, porém, agora, no contexto capitalista hegemonizado pelo mundo das finanças. As forças tradicionais foram rearticuladas, lideradas pela aliança político partidária entre o PSDB e o PFL, e convencidas de que, nas novas condições da economia internacional, era necessário, para manter o pacto de dominação conservador, que houvesse uma mudança de estratégia em relação ao papel do Estado na sociedade. A negação do papel do Estado como agente produtivo direto e como provedor de políticas sociais seria o cerne das mudanças que se faziam necessárias para a manutenção do pacto conservador de dominação (Fiori, 1998).

Dessa forma, os governos do Presidente Fernando Henrique Cardoso (1995-2002) conduziram a implementação de uma integração neoliberal do Brasil ao capital global e suas consequências políticas, econômicas e sociais foram introduzidas a partir da manutenção de nosso tradicional pacto conservador. Assim, pode-se dizer que se efetivou uma verdadeira "contrarreforma" do Estado brasileiro (Behring, 2003), retroagindo, de certa maneira, ao impulso - ainda que frágil - da nova letra constitucional.

A consequência administrativa do projeto de transnacionalização radical, presente no Plano Diretor da Reforma do Aparelho do Estado (PDRAE), conduzida pelo ministro Bresser Pereira, implicou uma forte coordenação das ações e a redução da intervenção do Estado na sociedade, tanto como setor produtivo quanto como provedor de políticas sociais. Por um lado, deu continuidade à concentração de poder burocrático herdada da ditadura e, por outro, a diminuição da burocracia estatal cujo horizonte, a despeito do que se alegava, foi desenhado por uma orientação dura de ajuste fiscal. Nesse movimento, a dimensão administrativa sofreu também as consequências do pacto de dominação estabelecido, como mediação para efetivação de uma nova articulação nos marcos da integração neoliberal e manutenção dos grupos historicamente no poder. Não se tratou de uma mera aversão ao Estado, mas de uma refuncionalização específica dele. Menor Estado para o social e maior Estado para o capital.

Para realizar essas mudanças administrativas, será efetivada a contrarreforma administrativa, formalizada no PDRAE, fundamentada teoricamente nos pressupostos da teoria da escolha pública (Andrews \& Kouzmin, 1998).

Andrews e Kouzmin (1998) desmontam qualquer possibilidade de separação entre os fundamentos da proposta de contrarreforma administrativa de FHC e a perspectiva da teoria da escolha pública. Para exemplificar, os autores destacam a relação entre a ideia de redução do Estado, defendida por Bresser Pereira, e a teoria da escolha pública, na medida em que tal teoria defende essa concepção "tanto pelo pressuposto de que os políticos agem para 
maximizar os votos ou de que burocratas agem para maximizar o orçamento de seus bureaux" (Andrews \& Kouzmin, 1998, p.106) Outro aspecto que os autores destacam é sobre a identificação entre a proposta presente no Plano Diretor de constituir "quase-mercados" para o desenvolvimento dos serviços sociais e a defesa da "expansão da analogia de mercado para a esfera política e, portanto, para os serviços públicos e sociais" (Andrews \& Kouzmin, 1998, p.108) feita pela teoria da escolha pública. Esses dois eixos fundamentais do PDRAE expressam de forma inequívoca sua vinculação à teoria escolha pública.

Nesse sentido, a proposta da "Administração Pública Gerencial", conforme denomina Bresser Pereira (1996), pautou-se na já aludida centralização burocrática, via núcleos estratégicos do governo combinada com a descentralização e flexibilização burocrática, via agências executivas/reguladoras, organizações sociais e o processo de terceirização de serviços e parcerias.

Através da centralização burocrática, que se configura como a estruturação de uma burocracia monocrática, viabiliza-se a coordenação das ações necessárias para o projeto de transnacionalização. Por intermédio da flexibilização da burocracia alcançam-se ao menos dois objetivos: diminuição de gastos públicos para contribuir com o ajuste fiscal e redução do poder da burocracia permanente. Na prática, como já aludido, obstrui-se a possibilidade de que essa forma administrativa funcionasse como mediação para levar adiante o impulso de universalização de direitos. Tal mediação provocará, além disso, a difusão ideológica do pensamento único economicista e a garantia de um poder coercitivo e discricionário da burocracia monocratizada, que definirá padrões formais para repasse de recursos públicos.

Em decorrência de sua análise acerca da crise econômica dos anos 1980 enquanto uma crise do Estado - crise fiscal, crise do modo de intervenção e crise do modelo burocrático de administração - Bresser-Pereira define a estratégia social-liberal como aquela que tem como prioridade a orientação para o mercado, afirmando que "a interpretação da crise e a correspondente estratégia social-liberal tomam emprestado do paradigma neoliberal a sua orientação ao mercado e a crença de que as funções do Estado foram severamente distorcidas" (Bresser Pereira, 1996, p. 20) - e isso em contraste com a entrevista contida na presente edição, de que sua propositura "não é neoliberal, além de eu ser profundamente contra o neoliberalismo por ser uma ideologia regressiva; reacionária e regressiva". Assim, completa o autor, "reformas econômicas orientadas ao mercado, privatização, desregulamentação, liberalização comercial, assim como disciplina fiscal e as políticas monetárias restritivas, são maneiras de reformar e fortalecer o Estado, de aumentar a sua governança, e não de enfraquecê-lo" (Bresser Pereira, 1996, p. 22). Ou seja, Bresser Pereira defende um receituário neoliberal para a reforma do Estado e da Administração Pública. Se a teoria da escolha pública se constituiu como o referencial teórico, a concepção neoliberal foi a essência econômica e política constitutiva do PDRAE.

Em relação aos aspectos institucionais do Plano, que dão forma à orientação teórica e política que o fundamenta, podemos destacar três mecanismos que consideramos centrais (SOUZA FILHO, 2011). Vejamos.

O primeiro mecanismo estava voltado, por um lado, para a redução do aparelho do Estado (o que provocaria um impacto imediato nas contas públicas), via privatização, terceirização, extinção de órgãos e focalização dos gastos sociais e, por outro lado, para a centralização e fortalecimento dos núcleos de decisão e controladores das políticas (núcleos estratégicos).

Borges (2001) destaca que a proposta de autonomia do Banco Central e a Lei de Responsabilidade Fiscal configuram-se como estratégias para consolidar essa forma administrativa fundada na centralização burocrática. Pelo lado da estratégia de redução dos gastos públicos, encontraremos a diminuição da estrutura burocrática da administração pública. A Emenda Constitucional no 19 e o processo de terceirização são expressões emblemáticas dessa estratégia.

O trabalho de Rezende (2004) é essencial para identificarmos a ligação umbilical entre a redução do quadro burocrático e a finalidade do ajuste fiscal. $O$ autor mostra que houve grande cooperação dos ministérios econômicos com o Ministério da Administração e Reforma do Estado (MARE) para reduzir os custos de pessoal da administração pública, devido a sua importância para a obtenção do ajuste fiscal. De acordo com Rezende (2004), o MARE foi extremamente eficiente, pois, de 1995 a 1999, a despesa com pessoal passou de $56,2 \%$ da receita corrente líquida para $39,7 \%$, e o número de funcionários públicos civis do poder executivo caiu de 630.763, em 1995, para 536.321, em 2002.

O segundo mecanismo reorganizava a relação entre formulação e implementação de políticas, redefinindo a relação de controle, através da descentralização e estabelecimento de critério de performance, que seriam acompanhados via contratos de gestão, a partir da transformação de determinados órgãos administrativos em organizações sociais ou em agências executivas. Por outro lado, essa mudança institucional também levaria a uma maior interação entre o poder público e o terceiro setor.

Nesse sentido, na lógica do Plano Diretor, a mudança institucional visava manter a situação de ajuste fiscal (objetivo primário) e melhorar a eficácia e eficiência das agências administrativas, através da proposta clássica gerencialista de combinar centralização burocrática (núcleo estratégico, formado pelo presidente, ministros e cúpula dos ministérios) com flexibilização gerencial (Agências Executivas; Agências Reguladoras; e Organizações Sociais/OS e Organizações da Sociedade Civil de Interesse Público/OSCIP).

A despeito de um discurso centrado na eficiência, mantiveram os excessivos cargos de confiança, intensificou-se a terceirização de serviços (estratégia de contratação de servidores periféricos e de níveis intermediários e operacionais), foi ampliada a ação pulverizada de programas sociais realizados em parceria com organizações da sociedade civil e refuncionalizou-se a liberação das emendas parlamentares. Os recursos disponíveis para a efetivação desses mecanismos ficaram sob o controle do centro de decisão política e burocrática. 
Sendo assim, entendemos que nesse quadro de contrarreforma do Estado e de contrarreforma gerencial produziu-se o estreitamento de condições para a ampliação e universalização de direitos e a redução das possibilidades de construção e fortalecimento da espinha dorsal administrativa necessária à condução de políticas públicas universalistas. Sem os meios quantitativa e qualitativamente necessários, inviabilizou-se esse caminho em benefício de uma integração subordinada ao capital global.

Estes elementos apresentados indicam nossa análise do PDRAE. Essa foi a forma que encontramos de também participar dos debates sobre o significado do Plano e seus impactos. Consideramos que essa breve exposição junto à riqueza dos artigos presentes na edição, ora publicada, permitirá aos leitores refletir com segurança sobre diferentes dimensões e concepções que permeiam as polêmicas acerca desta temática.

\section{A Revista APGS sobre o PDRAE}

Trata-se de uma edição que recebeu considerável atenção e resposta dos estudiosos da temática. Recebemos ao todo 41 artigos, um número considerado alto para uma chamada temática. Os artigos foram submetidos por diferentes pesquisadores de distintas áreas do conhecimento, empregando modalidades teórico-metodológicas diferenciadas e que foram submetidos a rigorosos avaliadores de várias partes do país. Isso mostra que o assunto é candente.

De todo o processo de avaliação, resultaram 09 textos finais que agora trazemos ao público. Os trabalhos são sem dúvidas diversos e guardam contraditoriedades entre si em razão do próprio caráter do esforço de reforma do Estado. Se a reforma foi bem-sucedida ou não, se ele já encontrou seu término ou não, são pontos de divergência que os textos agora tornados públicos provocam os leitores interessados na história recente da administração pública no Brasil.

Nesse sentido, iniciamos a edição com a contribuição de José Ricardo Vargas de Faria e José Henrique de Faria. O artigo, cujo título é A Concepção de Estado e a Administração Pública no Brasil no Âmbito do Plano Diretor de Reforma do Estado, apresenta uma importante discussão crítica ao ideário do Plano Diretor de Reforma do Estado, aportando uma fundamentação em Octavio lanni e Nicos Poulantzas para demarcar o Estado capitalista em suas bases materiais. A propositura angular é que a reforma levada a cabo no Brasil, circunscrita à eficiência do aparelho administrativo, não continha qualquer vestígio de inclusão social. O texto procura apontar que a direção da reforma é dada pelo imperativo da economia, fazendo do Estado um fator de coesão dos interesses dominantes. Assim, e nas palavras dos próprios autores, "as políticas patrocinadas pelo Estado puderam conferir maior competitividade aos empreendimentos produtivos diante do processo de globalização".

Na sequência, o artigo Governança Pública em Saúde PósReforma Gerencial no Brasil: Reconciliando Perspectivas para uma Análise Multinível, de Fernanda Filgueiras Sauerbronn, procura desbravar as nuances da governança como processo complexo e flutuante que se desdobra na interatividade de atores públicos e privados. A contribuição principal do artigo está na fundamentação acerca do conceito de codeterminação que mira, precisamente, numa análise multinível de práticas sociais desses atores aludidos, as lógicas que se embatem, os mecanismos e instrumentos de gestão e a repartição do poder entre os atores. $O$ texto alude às barganhas políticas intensificadas com a reforma gerencial que incluiu novos atores numa lógica da "competição administrada", sobretudo no provimento de serviços na área da saúde. Revela-se uma crescente influência dos interesses privados nesse processo.

O artigo seguinte, de Claudio Roberto Marques Gurgel, polemiza com os fundamentos orientadores da reforma, colocando em destaque o argumento de uma alegada crise do Estado. O trabalho, cujo título é Para Além da Reforma do Estado - Crises e Limites da Razão Liberal, procura demonstrar que, em verdade, a reforma no Brasil esteve orientada ao atendimento da crise do mercado que, no período, padecia de uma superacumulação de capitais em razão de obstáculos à "revalorização" na produção fordista. Dar vazão a esses capitais foi a força motriz das privatizações e de um novo modelo gerencial cuja pedra angular é a que afirma a gestão privada como paradigma da administração pública. A reforma, como se lê no artigo em questão, "interessou à parcela da sociedade que tem sido beneficiária de todas as reformas conservadoras das desigualdades pessoais e regionais".

Na sequência aparece o artigo Terceirização e Precarização do Trabalho na Política Pública de Assistência Social, de Maria Érica Ribeiro Pereira, Mônica Mota Tassigny e Fabiana Pinto de Almeida Bizarria, que procura identificar as implicações da terceirização como concreção de preceitos neoliberais, no âmbito da Política de Assistência Social. Tendo por corte, portanto, a gestão do trabalho na Assistência Social, a pesquisa aponta principalmente para os rebatimentos da reforma e sua consequente degradação do trabalho. Na Assistência Social a terceirização implicou retrocessos, revitalizando inclusive elementos tradicionais e certa desprofissionalização. Implicou igualmente numa divisão social do trabalho entre assistentes sociais terceirizados e estatutários de maneira que os primeiros são alocados nas funções menos atrativas. Os resultados, no geral, são opostos aos pretendidos pela reforma, aumentando desperdícios e alimentando vícios combatidos historicamente na administração pública brasileira.

O texto subsequente procura polemizar a alegada oposição frequentemente aludida entre, de um lado, maior presença do Estado e maiores políticas distributivistas e, de outro, o neoliberalismo. A Trajetória Ininterrupta da Reforma do Aparelho de Estado no Brasil: Continuidades nos Marcos do Neoliberalismo e do Gerencialismo, assinado por Maria Ceci Araujo Misoczky, Paulo Ricardo Zilio Abdala e Luiza Araujo Damboriarena, procura tratar o neoliberalismo como, em verdade, "um projeto de classe" não contraditório à presença estatal e posto em movimento em base gerencialista que procura generalizar a lógica de mercado para todas as esferas da vida. O gerencialismo é tematizado - seguindo as trilhas de Lukács - como ideologia com força material que emerge principalmente no contexto da crise dos anos de 1970 e é nesse contexto que o artigo circunscreve a Nova Administração Pública, 
abarcando os processos ainda em continuidade da reforma no Brasil.

Eliana Vieira Turíbio e Eloisa Helena Santos assinam o texto $A$ Reforma do Estado e a Gestão Democrática na Universidade Pública Brasileira. As autoras discutem a "hegemonia neoliberal" e as repercussões na área educacional, sobretudo na participação democrática na universidade pública brasileira. Ao considerar a participação social como elementos central na gestão democrática da educação, o artigo aponta para a contradição entre essa participação e o modelo gerencial. Há um embate de forças em que a resistência a esse modelo se agarra à autonomia universitária mobilizada por movimentos sociais. O processo de hegemonia de um modelo "estratégico-empresarial" resultou em uma participação nas universidades públicas que tendeu a se reduzir "ao compartilhamento da informação e à conscientização dos servidores sobre a missão institucional e sobre os resultados globais desejados" traçados por grupos de poder ou pela burocracia estatal externa.

Administração Pública Brasileira no Século XXI - Caminhamos para Alguma Reforma? escrito por Juliana de Fátima Pinto e Leonardo Tadeu dos Santos, recupera as três reformas realizadas no Brasil (1930, 1967 e 1995) para analisar o período dos governos petistas. A posição do texto se revela no entendimento de que a suposta transição feita por via das reformas históricas entre modelos patrimonial, burocrático e gerencial é falsa em razão de os modelos não serem estanques e se permearem. A pesquisa aponta que nos governos Lula a propositura de uma modernização era mediada pelo desempenho e produtividade e que isso convivia com avanços progressistas pela ampliação do diálogo com movimentos sociais. O primeiro aspecto da dualidade se marca pela manutenção da agenda da década de 1990. Não obstante, é nos governos Dilma que se apreende maior alinhamento à "política gerencialista" dos anos de 1990 , sobretudo no aspecto tangente ao ajuste fiscal. No conjunto da análise, sobressalta-se que, a despeito dessas não rupturas com o modelo gerencialista, conseguiu-se algum direcionamento em vista de um modelo de uma administração societal.

$\mathrm{Na}$ mesma tendência de recuperar as reformas históricas, Elisa Zwick desenvolve, em O Poder Político-Burocrático na Gestão Pública Brasileira: uma Crítica de seus Marcos Reformistas à Luz de Adorno, uma análise crítica ao caráter "danificado" da gestão pública no Brasil, nos marcos de um Estado capitalista. A análise procura demonstrar historicamente que o Estado, cumprindo a função de atender aos imperativos do capital, manteve-se como alavanca para a reprodução dos interesses conservadores da formação capitalista. Precisamente as reformas tiveram essa funcionalidade. No enlace entre Estado e as estruturas político-burocráticas apenas é possível as "amarrações técnicas da racionalidade instrumental" que produz um "déficit de aceitação das contradições de classe" por parte dos próprios operadores da gestão pública.

Por fim, mas não menos importante, o texto Reforma Gerencial em Contexto Local: Estudo Comparado dos Municípios de Osasco e Niterói, de autoria de Marilia Sorrini Peres Ortiz e Anny Karine Medeiros, demonstra o nível de desenvolvimento da governança participativa nas municipalidades indicadas no título. Considerando que mesmo após décadas de reforma do Estado, o texto sugere que o "ideal de eficiência" permanece subterrâneo no setor público e se apresenta com renovadas roupagens. No plano das municipalidades, a pesquisa mostra que a participação tende a se limitar à etapa de elaboração dos planos estratégicos sem se estender para a etapa de implementação das políticas públicas. $\mathrm{O}$ texto denota que as "experiências mostram que há tentativas em curso, e principalmente, demonstram que há espaço para melhorias na gestão pública, sendo necessário avançar nos instrumentos e modelos que permitirão uma gestão pública mais eficiente".

As diferenças teóricas e políticas entre os textos ficam consideravelmente demarcadas nessa curta apresentação que, claro, não substitui a leitura dos textos propriamente ditos. $\mathrm{E}$ aqui deixamos nosso convite à reflexão da comunidade acadêmica, dos gestores públicos, dos membros das organizações sociais e movimentos sociais sobre o conjunto dos textos que nos permite compreender melhor o movimento ainda não finalizado que remonta 1995.

Além dos artigos, trazemos também uma entrevista realizada com Bresser Pereira em 2016 por meio da qual emergem inúmeras questões tangentes aos textos aqui apresentados. Agradecemos a Bresser Pereira pela concessão e a Amon Narciso de Barros por ter conduzido a entrevista em São Paulo e ao professor Frederico Lustosa por ter colaborado na preparação do roteiro de entrevista. Agradecemos também a Arthur Bastos, Gabriela Cavalcanti, Júlia Gava, Leandro Theodoro Guedes, Marlon Maia, Paula Dias e Ruy Silva pela transcrição inicial da entrevista.

Não poderíamos terminar essa apresentação sem agradecer a todo o esforço da equipe editorial, especialmente na figura do editor Wescley Xavier. Devemos agradecer também aos inúmeros avaliadores que cederam tempo e atenção para que fosse possível chegar ao resultado do processo avaliativo.

\section{Referências Bibliográficas}

Andrews, C. \& Kouzmin, A (1998). O discurso da nova administração pública. In: Lua Nova. São Paulo, CEDEC.

Behring, E. R. (2003). Brasil em contra-reforma: desestruturação do Estado e perda de direitos. São Paulo, Cortez.

Borges, A. (2001). Democracia VS. Eficiência: a teoria da escolha pública. In: Lua Nova. № 53. São Paulo. CEDEC.

Bresser Pereira, L. C. (1996). Crise econômica e reforma do Estado no Brasil. São Paulo, Editora 34

Cardoso de Mello, J. M. (1998). O Capitalismo Tardio. 9ª edição. São Paulo. Brasiliense.

Coutinho, C. N. (1992). Democracia e socialismo: questões de princípio \& contexto brasileiro. São Paulo, Cortez.

Fernandes, F. (1981). A revolução burguesa no Brasil. $3^{\text {a }}$ edição. Rio de Janeiro. Zahar Editores.

Fiori, J. L. (1995). Em busca do dissenso perdido. Rio de Janeiro: Insight. . (1998). Os moedeiros falsos. 5ª edição. Petrópolis: Vozes.

Marx, K. (1996). Para a crítica da economia política. Os Pensadores. São Paulo: Nova Cultural.

Marx, K. (2011a). A guerra civil na França. São Paulo: Boitempo.

Marx, K. (2011b). O 18 Brumário de Luiz Bonaparte. São Paulo: Boitempo.

OLIVEIRA, F. (2003). Crítica à razão dualista. O ornitorrinco. São Paulo. Boitempo.

Paço Cunha, E. (2016). Que fazer da burocracia de estado? Do indiferentismo às reciprocidades. Administração Pública e Gestão Social,(8)1, 15-26..

Rezende, F. C. (2004). Pôr que falham as reformas administrativas? Rido de Janeiro: Editora FGV.

Souza Filho, R. (2011). Gestão Pública e Democracia: a burocracia em questão. Rio de Janeiro: Lumen Juris.

Souza Filho, R. \& Gurgel, C. (2016). Gestão Democrática e Serviço Social: princípios e propostas para a intervenção crítica. São Paulo, Cortez. 